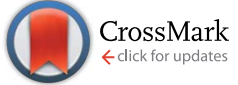

Cite this: J. Mater. Chem. A, 2015, 3, 8300

Received 8th February 2015

Accepted 12th March 2015

DOI: $10.1039 / \mathrm{c} 5 \operatorname{ta} 01058 \mathrm{f}$

www.rsc.org/MaterialsA

\section{Efficient solar hydrogen production from neutral electrolytes using surface-modified $\mathrm{Cu}(\mathrm{In}, \mathrm{Ga}) \mathrm{Se}_{2}$ photocathodes $\uparrow$}

\author{
Hiromu Kumagai, ${ }^{a}$ Tsutomu Minegishi, ${ }^{a}$ Naotoshi Sato, ${ }^{\text {bc }}$ Taro Yamada, ${ }^{d}$ Jun Kubota ${ }^{a}$ \\ and Kazunari Domen*a
}

\begin{abstract}
The effects of a phosphate buffer electrolyte and surface modification with thin conductor layers on the photoelectrochemical properties of $\mathrm{CdS}$ and Pt-modified polycrystalline $\mathrm{Cu}(\mathrm{In}, \mathrm{Ga}) \mathrm{Se}_{2}$ (CIGS) photocathodes were investigated. The photocurrent obtained from Pt/CdS/CIGS electrodes, in which the CIGS layer was fabricated by co-evaporation using a three stage method, clearly increased in a phosphate buffer electrolyte solution as a result of promotion of the hydrogen evolution reaction. The half-cell solar-to-hydrogen efficiency ( $\mathrm{HC}$-STH) of this device reached a maximum of $5.4 \%$ at $0.30 \mathrm{~V}_{\mathrm{RHE}}$ even under neutral conditions. Furthermore, significant enhancement of the hydrogen evolution reaction on a CIGS photocathode by surface modification with thin conductor layers was observed. The enhancement was due to the promoted charge transfer between the underlying photocathode and water through the Pt catalyst. The HC-STH of a CIGS photocathode modified with a conductive Mo/Ti layer (Pt/Mo/Ti/CdS/CIGS) was as high as $8.5 \%$ at $0.38 \mathrm{~V}_{\mathrm{RHE}}$, a value that exceeds those previously reported for photocathodes based on polycrystalline thin films.
\end{abstract}

\section{Introduction}

Due to rapidly increasing demand for energy, there is presently a need to reduce our dependence on fossil fuels and, concurrently, to reduce emissions of the greenhouse gas carbon dioxide, so as to ensure sustainable development in the future. ${ }^{1}$ Modern technologies for obtaining renewable energies, such as biofuels,$^{2}$ photovoltaics ${ }^{3}$ concentrated solar thermal ${ }^{4}$ and wind turbines, ${ }^{5}$ have attracted much attention over the past few decades. However, fluctuations in time and in localization (or inhomogeneous distribution) of such renewable energies are two major problems that must be overcome to allow their widespread use. The conversion of renewable energy to storable chemical energy forms may serve as a solution to these issues. ${ }^{6}$ Sunlight-driven photoelectrochemical (PEC) water splitting is a potential means of directly obtaining hydrogen as a clean, sustainable and storable fuel. ${ }^{7,8}$ Since the discovery of the socalled Honda-Fujishima effect, ${ }^{9}$ many researchers have

\footnotetext{
${ }^{a}$ Department of Chemical System Engineering, University of Tokyo, 7-3-1 Hongo, Bunkyo-ku, Tokyo 113-8656, Japan. E-mail: domen@chemsys.t.u-tokyo.ac.jp

${ }^{b} J a p a n$ Technological Research Association of Artificial Photosynthetic Chemical Process (ARPChem), 5-1-5 Kashiwanoha, Kashiwa-shi, Chiba 277-8589, Japan

${ }^{c}$ FUJIFILM Corporation, 577, Ushijima, Kaisei-Machi, Ashigarakami-gun, 258-8577 Kanagawa, Japan

${ }^{d}$ Department of Chemical System Engineering, The University of Tokyo, 5-1-5 Kashiwanoha, Kashiwa-shi, 277-8589 Chiba, Japan
}

$\dagger$ Electronic supplementary information (ESI) available. See DOI: $10.1039 / \mathrm{c} 5 \mathrm{ta} 01058 \mathrm{f}$ intensively investigated PEC water splitting. However the development of a photoelectrode material suitable for this process has been a significant challenge, due to many restrictive requirements: stability under water splitting conditions and a sufficiently small band gap together with a suitable band structure. In PEC water splitting, band bending induced at solid-liquid interfaces plays a crucial role in driving the water splitting reaction by providing charge separation. Specifically, $\mathrm{n}$ - and p-type semiconductor materials act as the photoanode and photocathode, respectively, since the charge separation polarity at the solid-liquid interface is switched by the conductivity type of the photoelectrode. Because of the important role of band bending, modification of the solid-liquid interface, such as through the introduction of multilayer structures, is an essential aspect of the development of photoelectrode materials so as to obtain efficient hydrogen evolution. In general, even if the bandgap of the photoelectrode material is less than $1.23 \mathrm{eV}$, equivalent to the change in Gibbs free energy required for water splitting to hydrogen and oxygen, a combined photocathode/photoanode system will only be able to drive overall water splitting provided that the overlapping respective bandgaps of the two electrodes exceed the hydrogen and oxygen evolution potentials.

Many types of photoelectrodes have been investigated for PEC water splitting, such as $\mathrm{Si}^{10-14}$ phosphides, ${ }^{\mathbf{1 5 - 1 8}}$ chalcogenides, ${ }^{19,20}$ oxides, ${ }^{21-23}$ nitrides ${ }^{24-26}$ and oxynitrides. ${ }^{27-29}$ Recently, various $\mathrm{Cu}$ chalcogenide materials, including $\mathrm{Cu}(\mathrm{In}, \mathrm{Ga}) \mathrm{Se}_{2},{ }^{30}$ $\mathrm{CuGaSe}_{2},{ }^{31,32} \mathrm{CuGa}_{3} \mathrm{Se}_{5},{ }^{33,34}$ (Ag,Cu)GaSe ${ }_{2},{ }^{35,36} \mathrm{CuInS}_{2},{ }^{37-39}$ and 
$\mathrm{Cu}_{2} \mathrm{ZnSnS}_{4}{ }^{40}$ have received significant attention as possible photocathodes for PEC water splitting, due to their specific characteristics: p-type semiconducting properties, high optical absorption coefficients greater than $10^{5} \mathrm{~cm}^{-1}$, ability to promote stable hydrogen evolution in response to irradiation, and usability in the polycrystalline state. However, the half-cell solar-to-hydrogen efficiency (HC-STH) of these materials is insufficient. The HC-STH of these compounds is less than $2 \%$ in alkaline solution even with successful surface modification with catalysts and n-type semiconductor materials, such as Pt and CdS.

As noted above, $\mathrm{Cu}(\mathrm{In}, \mathrm{Ga}) \mathrm{Se}_{2}$ (CIGS) is a potential candidate as a photocathode material. This compound has a light absorption edge at approximately $1050 \mathrm{~nm}$ in conjunction with a composition in which $\mathrm{In} /(\mathrm{In}+\mathrm{Ga})=0.7$. The photon frequency in response to AM 1.5G solar irradiation between the $\mathrm{UV}$ and $1050 \mathrm{~nm}$ is equivalent to $-42.3 \mathrm{~mA} \mathrm{~cm}{ }^{-2}$, such that a CIGS photoelectrode is expected to exhibit this current (assuming $100 \%$ quantum efficiency) up to the wavelength of the adsorption edge. In a previous report, however, the photocurrent was found to have a limit of approximately $-12 \mathrm{~mA} \mathrm{~cm}^{-2}$ at $0 \mathrm{~V}_{\mathrm{RHE}}$ even under Xe lamp irradiation, which is several times more powerful than simulated sunlight. ${ }^{30}$ Jacobsson et al. demonstrated the potential of CIGS to function as a light absorber in a photocathode, using a PV-electrolysis setup, and observed a cathodic current in excess of $20 \mathrm{~mA} \mathrm{~cm}{ }^{-2}$, although in this case the CIGS was situated entirely outside of the electrochemical cell. ${ }^{41}$

In the present study, we focus on the effects of a phosphate buffer electrolyte and surface modification with thin conductor layers on the PEC properties of CdS and Pt-modified CIGS photocathodes as a means of increasing the performance of photocathodes during PEC water splitting. We first examined the use of a concentrated phosphate buffer solution as an electrolyte in place of a more typical alkaline solution and determined that the modified CIGS photocathodes showed enhanced hydrogen evolution in such a solution. To further enhance the hydrogen evolution under simulated sunlight, surface modification with thin conductor layers with finite inplane conductivity was investigated based on a novel concept in which the conductor layers mediate the charge transfer between the underlying photocathode and the water through the Pt catalyst, with no loss of the advantage of using solid-liquid interfaces. It was found that a CdS/CIGS photocathode modified with a Pt catalyst and a thin $\mathrm{Mo} / \mathrm{Ti}$ layer generated a significantly higher cathodic photocurrent and HC-STH, even in neutral solution.

\section{Experimental}

\section{Preparation of $\mathrm{Cu}(\mathrm{In}, \mathrm{Ga}) \mathrm{Se}_{2}$ thin films}

$\mathrm{Cu}(\mathrm{In}, \mathrm{Ga}) \mathrm{Se}_{2}$ (CIGS) films were deposited onto substrates of Mocoated soda-lime glass by a three-stage method, using a molecular beam epitaxy apparatus. ${ }^{42-44}$ The deposition chamber was equipped with Knudsen cells of elemental $\mathrm{Cu}$, In, $\mathrm{Ga}$ and Se. Prior to the film deposition, the substrate was annealed at $823 \mathrm{~K}$ under high vacuum for $1 \mathrm{~h}$, followed by treatment in a $\mathrm{H}_{2}$ atmosphere of $2 \times 10^{-3} \mathrm{~Pa}$ for $30 \mathrm{~min}$. Applied deposition rates of $\mathrm{Cu}, \mathrm{In}, \mathrm{Ga}$ and Se sources in film growth were set to 0.051 , $0.050,0.015$ and $0.9 \mathrm{~nm} \mathrm{~s}^{-1}$, respectively. The substrate temperature in the first stage was set at $573 \mathrm{~K}$, while the second and third stage temperatures were fixed at $823 \mathrm{~K}$.

\section{Modification with an n-type CdS layer}

CdS layers were formed on the CIGS thin films by the chemical bath deposition (CBD) method. ${ }^{31,32,43,45}$ A $70 \mathrm{~mL}$ portion of a distilled water solution containing $\mathrm{Cd}\left(\mathrm{CH}_{3} \mathrm{COO}\right)_{2}$ (Kanto Chemical, 98.0\%), $\mathrm{SC}\left(\mathrm{NH}_{2}\right)_{2}$ (Kanto Chemical, 98.0\%) and $\mathrm{NH}_{3}$ (Wako Pure Chemical, $28 \mathrm{wt} \%$ ) concentrations of $25 \mathrm{mM}$, $375 \mathrm{mM}$ and $14 \mathrm{wt} \%$, respectively, was used as the chemical bath. During the CBD process, the bath temperature was gradually increased from 273 to $328 \mathrm{~K}$ over the span of approximately $8 \mathrm{~min}$. The total deposition time was $14 \mathrm{~min}$.

\section{Modification with a thin conductor layer}

Thin conductor layers of Ti and Mo were formed on the surfaces of CdS/CIGS films by RF magnetron sputtering using a high purity Ti target (High Purity Chemicals, 99.98\%) and a Mo target (High Purity Chemicals, 99.98\%) in an Ar atmosphere of $1.2 \times$ $10^{-1} \mathrm{~Pa}$ at room temperature, applying an RF power of $30 \mathrm{~W}$. A deposition time of 3 min was employed to obtain conductor layers of approximately $3 \mathrm{~nm}$ thick.

\section{Modification with Pt}

Pt particles intended as hydrogen evolution catalysts were deposited on the prepared electrodes by photo-assisted electrodeposition. The Pt deposition was performed using a threeelectrode PEC system, the details of which are provided in the Photoelectrochemical measurements section. The resulting electrodes were exposed to simulated sunlight (adjusted to AM $1.5 \mathrm{G}$ at $100 \mathrm{~mW} \mathrm{~cm}^{-2}$ ) generated using a solar simulator (SANEI Electric, XES-40S2-CE) while immersing in a solution containing $10 \mu \mathrm{M} \mathrm{H}_{2} \mathrm{PtCl}_{6}$ (Kanto, 98.5\%), $50 \mu \mathrm{M} \mathrm{NaOH}$ (Wako, from $0.1 \mathrm{M}$ solution) and $0.1 \mathrm{M} \mathrm{Na}_{2} \mathrm{SO}_{4}$ at a potential of $-0.1 \mathrm{~V}$ versus $\mathrm{Ag} / \mathrm{AgCl}$ for $30 \mathrm{~min}$.

\section{Characterization of synthesized electrodes}

Structural and compositional analyses of the synthesized CIGS electrodes were performed using scanning electron microscopy (SEM; S-4700 or SU8020, Hitachi High-tech) and energy dispersive X-ray spectroscopy (EDX; EMAX-7000, Horiba), respectively. Transmission spectroscopy (V-560, Jasco) was employed to determine the absorption edges. The surface chemistries of CIGS electrodes were analyzed using X-ray photoelectron spectroscopy (XPS; JPS-9000, JEOL). To estimate the Faradaic efficiency of the CIGS electrodes during the generation of $\mathrm{H}_{2}$ and $\mathrm{O}_{2}$, gaseous products were analyzed using micro-gas chromatography (GC, GC3000A, Inficon) in an airtight three-electrode configuration under simulated sunlight. The sheet resistances of the thin conductor films deposited on a glass plate were measured using a four-point probe method (Loresta-GP MCP-T610, Mitsubishi Chemical Analytech). 


\section{Photoelectrochemical measurements}

A typical three-electrode setup was used during the PEC measurements. A Pt wire and $\mathrm{Ag} / \mathrm{AgCl}$ in saturated $\mathrm{KCl}$ aqueous solution were employed as the counter and reference electrodes, respectively. The PEC measurements were performed under an Ar atmosphere using an aqueous solution containing $0.1 \mathrm{M}$ $\mathrm{Na}_{2} \mathrm{SO}_{4}$ (pH adjusted to 9.5 by $\mathrm{NaOH}$ addition) or a mixed solution containing $0.5 \mathrm{M} \mathrm{Na}_{2} \mathrm{SO}_{4}, 0.25 \mathrm{M} \mathrm{Na}_{2} \mathrm{HPO}_{4}$ and $0.25 \mathrm{M}$ $\mathrm{NaH}_{2} \mathrm{PO}_{4}$ ( $\mathrm{pH}$ adjusted to 6.8 by $\mathrm{NaOH}$ addition) as the electrolyte. The potentials obtained from each measurement were converted into values against a reversible hydrogen electrode (RHE) using the Nernst equation $\left(E_{\mathrm{RHE}}(\mathrm{V})=E_{\mathrm{Ag} / \mathrm{AgCl}}+0.199+\right.$ $0.059 \mathrm{pH}$ ). A solar simulator (XES-40S2-CE, SAN-EI Electric) applying AM $1.5 \mathrm{G}$ irradiation at $100 \mathrm{~mW} \mathrm{~cm}^{-2}$ was employed as the light source. The hypothetical HC-STH was calculated from the current-potential curves using the equation HC-STH $=\left|I_{\mathrm{ph}}\right|$ $\times\left(E_{\mathrm{RHE}}-E_{\mathrm{H}+/ \mathrm{H} 2}\right) / P_{\text {sun }} \times 100 \%$, where $I_{\mathrm{ph}}$ is the photocurrent density obtained under an applied bias of $E_{\mathrm{RHE}}, E_{\mathrm{H}+/ \mathrm{H} 2}$ is the equilibrium redox potential of hydrogen $\left(0 \mathrm{~V}_{\mathrm{RHE}}\right)$ and $P_{\text {sun }}$ is the power density of the incident solar energy $\left(100 \mathrm{~mW} \mathrm{~cm}^{-2}\right)$.

\section{Results and discussion}

The resulting CIGS electrode structures were characterized using SEM. The top view shown in Fig. 1(A) demonstrates that the electrode surface was composed of multifaceted grains with sizes on the order of several micrometers. The observed morphology reflected the crystal habit of CIGS and therefore the preparation conditions were considered to be appropriate with regard to generating the required degree of crystallinity. A cross-sectional view is presented in Fig. 1(B) and indicates that the prepared CIGS films consisted of columnar grains without grain boundaries between the film surfaces and backside contacts. The In/(In + Ga) and $\mathrm{Cu} /(\mathrm{In}+\mathrm{Ga})$ atomic ratios of an as-prepared CIGS film were determined to be 0.71 and 0.81 from EDX results and the absorption edge of a CIGS film grown directly on soda lime glass was found to be approximately $1050 \mathrm{~nm}$ based on its transmission spectrum (Fig. S1†). It was also confirmed by XRD measurements that the films have a chalcopyrite structure (Fig. S2 $\dagger$ ). From these results, it was evident that CIGS films with the desired characteristics had been obtained. The thickness of the modified CdS layer was approximately $60 \mathrm{~nm}$. It should be noted that these CIGS devices had the potential to generate a photocurrent of $-42.3 \mathrm{~mA} \mathrm{~cm}^{-2}$ under AM 1.5G irradiation based on an assumption of $100 \%$ quantum efficiency at wavelengths below $1050 \mathrm{~nm}$.
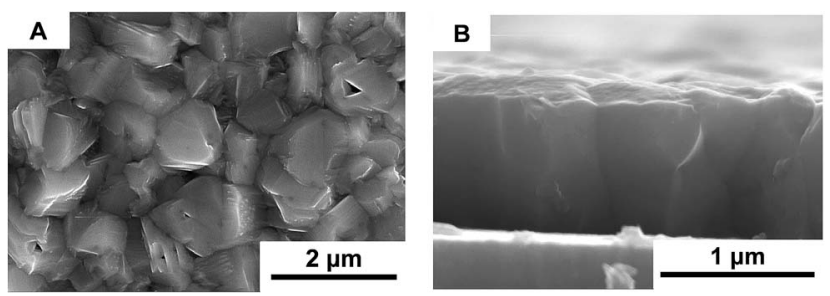

Fig. 1 SEM images of an as-prepared CIGS film: (A) top view and (B) cross-sectional view.
Fig. 2 shows the current-potential curves obtained for CIGS photocathodes modified with Pt and CdS (Pt/CdS/CIGS) under simulated sunlight in different electrolytes: an aqueous solution of $0.1 \mathrm{M} \mathrm{Na}_{2} \mathrm{SO}_{4} \mathrm{pH}$-adjusted to 9.5 by $\mathrm{NaOH}$ addition and a mixed aqueous solution of $0.5 \mathrm{M} \mathrm{Na}_{2} \mathrm{SO}_{4}, 0.25 \mathrm{M} \mathrm{Na}_{2} \mathrm{HPO}_{4}$ and $0.25 \mathrm{M} \mathrm{NaH}_{2} \mathrm{PO}_{4} \mathrm{pH}$-adjusted to 6.8 by $\mathrm{NaOH}$ addition. In both the $\mathrm{Na}_{2} \mathrm{SO}_{4}$ and mixed solutions, the Pt/CdS/CIGS photocathodes generated cathodic photocurrents under simulated sunlight at an applied potential of $>0 \mathrm{~V}_{\mathrm{RHE}}$. This result demonstrated that CIGS is capable of generating hydrogen through the conversion of photon energy under an external bias and irradiation by visible light, in agreement with previous reports. ${ }^{\mathbf{3 0 4 1}}$ The photocurrent obtained from a $\mathrm{Pt} / \mathrm{CdS} / \mathrm{CIGS}$ electrode increased remarkably in the phosphate buffer electrolyte and the maximum HC-STH efficiency obtained was $5.4 \%$ at $0.30 \mathrm{~V}_{\text {RHE }}$ (Fig. 5(B)), even under neutral conditions.

To elucidate the cause of the significantly different photocurrent values obtained from the two electrolytes, currentpotential hydrogen evolution reaction (HER) plots were generated from a polycrystalline Pt disk electrode rotating at 1600 rpm under dark conditions in each electrolyte. As shown in Fig. 3, when employing the $\mathrm{Na}_{2} \mathrm{SO}_{4}$ solution an applied potential of $-0.2 \mathrm{~V}_{\mathrm{RHE}}$ was required to generate a $1 \mathrm{~mA} \mathrm{~cm}{ }^{-2} \mathrm{HER}$ current, while the phosphate buffer solution required a much higher applied potential of only $-0.02 \mathrm{~V}_{\mathrm{RHE}}$. Based on these results, the observed difference in the cathodic photocurrent between the $\mathrm{Na}_{2} \mathrm{SO}_{4}$ and phosphate buffer solutions is believed to have resulted from variations in the HER at the surfaces of Pt particles deposited on the photocathodes. Auinger et al. have suggested that buffer species act to stabilize the $\mathrm{pH}$ in the vicinity of the electrode surface and to reduce the chemical bias, thus promoting the HER, and the present results appear to be in good agreement with this theory. ${ }^{46,47}$

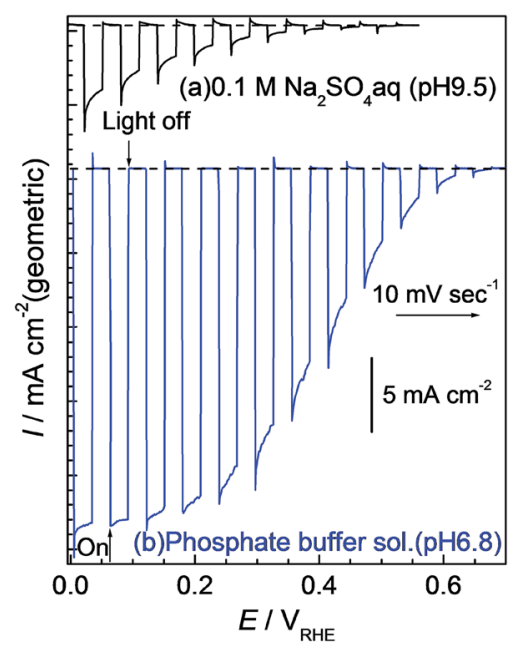

Fig. 2 Current-potential curves of a Pt/CdS/CIGS electrode in (a) 0.1 $\mathrm{M} \mathrm{Na}_{2} \mathrm{SO}_{4}$ (aq.) ( $\mathrm{pH}$ adjusted to 9.5 by $\mathrm{NaOH}$ addition) and (b) a mixed solution of $0.5 \mathrm{M} \mathrm{Na}_{2} \mathrm{SO}_{4}, 0.25 \mathrm{M} \mathrm{Na}_{2} \mathrm{HPO}_{4}$ and $0.25 \mathrm{M} \mathrm{NaH}_{2} \mathrm{PO}_{4}(\mathrm{pH}$ adjusted to 6.8 by $\mathrm{NaOH}$ addition) under AM $1.5 \mathrm{G}$ irradiation. The potential was swept toward the positive direction at $10 \mathrm{mV} \mathrm{s}^{-1}$. 


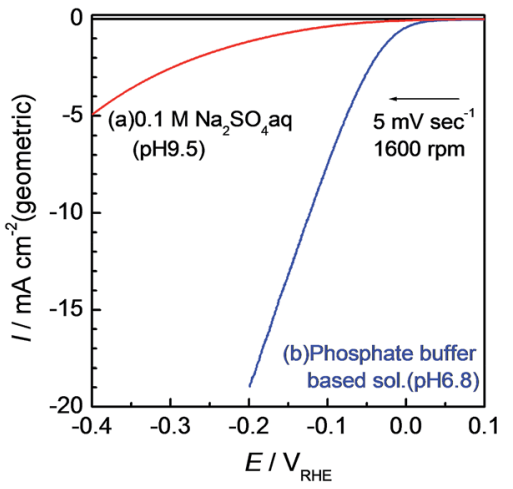

Fig. 3 Current-potential curves of a Pt disc electrode in (a) $0.1 \mathrm{M}$ $\mathrm{Na}_{2} \mathrm{SO}_{4}$ (aq.) ( $\mathrm{pH}$ adjusted to 9.5 by $\mathrm{NaOH}$ addition) and (b) a mixed solution of $0.5 \mathrm{M} \mathrm{Na}_{2} \mathrm{SO}_{4}, 0.25 \mathrm{M} \mathrm{Na}_{2} \mathrm{HPO}_{4}$ and $0.25 \mathrm{M} \mathrm{NaH}_{2} \mathrm{PO}_{4}$ (pH adjusted to 6.8 by $\mathrm{NaOH}$ addition) at $1600 \mathrm{rpm}$. The potential was swept toward the negative direction at $5 \mathrm{mV} \mathrm{s}^{-1}$.

One possible reason for the limited improvements seen in CIGS photocurrents could be related to issues regarding the interface between the CdS/CIGS phase and the Pt particles. As has been reported in the case of Si photocathodes, photocathodes incorporating Pt as an HER catalyst often exhibit lower onset potentials, possibly due to surface recombination at the interface. ${ }^{12}$ In addition, the quantity of photo-excited minority carriers required to charge the $\mathrm{Pt}$ particles to the hydrogen evolution potential must be able to reach the Pt particles. Thus, in the present study, surface modification with conductor layers was employed as a possible means of mitigating problems associated with interfacial contacts and charge migration to difficult-to-reach locations. The degree of contact between Pt particles and the photocathode should be improved by inserting the appropriate conductors at the interface between the two phases. In addition, as shown in Fig. 4, the electron-rich conductor layers should act as an intermediary to catch photoexcited electrons and transfer these electrons to the water via

(A) Conventional Pt/CdS/CIGS photocathode

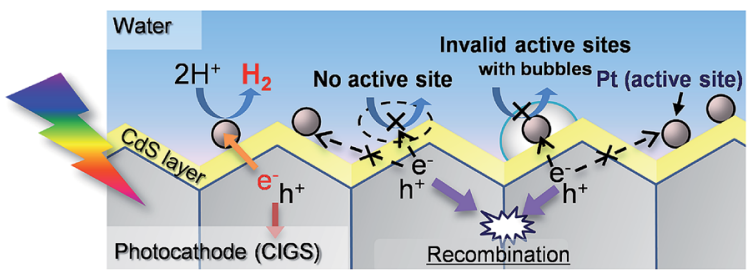

(B) Photocathode with conductor layer

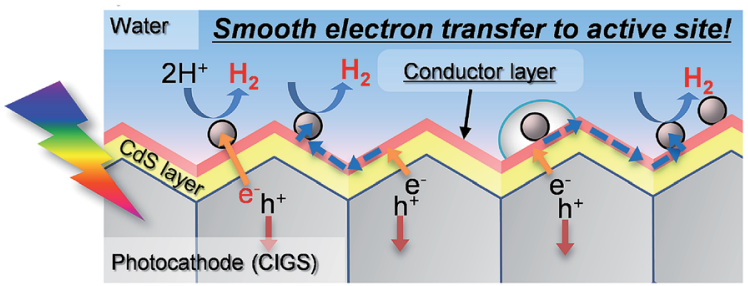

Fig. 4 A proposed mechanism for hydrogen evolution on the surfaces of irradiated photocathodes. the Pt particles. In the present study, Ti, Mo and Mo/Ti layers were examined as the conductor layers.

The current-potential curves obtained for Pt/CdS/CIGS photocathodes with conductor layers of $\mathrm{Ti}, \mathrm{Mo}$ and $\mathrm{Mo} / \mathrm{Ti}$ applied between the Pt and CdS layers are presented in Fig. 5(A). The application of a binary Mo/Ti layer increased both the photocurrent and the onset potential of the electrode, and this electrode also exhibited the highest values of these two performance parameters. It should be noted that the Pt/Mo/CdS/CIGS photocathode showed a lower cathodic photocurrent at a near onset potential ( $>0.5 \mathrm{~V}_{\mathrm{RHE}}$ ) compared to the other electrodes, although this same electrode demonstrated a higher cathodic photocurrent in a lower potential range $\left(<0.5 \mathrm{~V}_{\mathrm{RHE}}\right)$ compared to the Pt/Ti/CdS/CIGS and Pt/CdS/CIGS specimens. These results indicate that the Mo layer preferentially interfaces with the Pt particles to obtain a higher photocurrent, while at the interface between the Mo and the underlying CdS/CIGS there is presumably an undesirable electric contact which leads to surface recombination and drop of the onset potential, similar to the case of the reported Pt/Si electrode. ${ }^{12}$ On the other hand, the samples modified with Ti exhibited a higher onset potential compared to Pt/CdS/CIGS so that the Ti layer may undergo the necessary intimate contact with the underlying CdS/CIGS. Considering the Pt/Ti interface, since the Ti layer can have a $\mathrm{TiO}_{2}$ passivation layer, modification with only Ti could not achieve a significant improvement in the photocurrent. In contrast, the surface oxide layer of Mo is readily reduced and so Pt can be deposited onto the reduced Mo surface by photoassisted electrodeposition without the appearance of any interfering species at the interfaces between the Pt particles and the conductor layer. Thus a binary Mo/Ti layer generates a larger photocurrent than modification with only Ti. As can be seen from Fig. 5(B), the HC-STH value of the Mo/Ti-modified electrode had a maximum of $8.5 \%$ at $0.38 \mathrm{~V}_{\mathrm{RHE}}$. Interestingly, this value is higher than those previously reported for photocathodes based on polycrystalline thin films. ${ }^{18,31,36,38-40}$ The $\mathrm{pH}$ dependence of current-potential curves of the Pt/Mo/Ti/CdS/ CIGS photoelectrode is shown in Fig. S3. $\uparrow$ The electrode showed a higher onset potential and photocurrent in solution of pH 6.8 than in others. We also examined the effect of the Mo/Ti layer
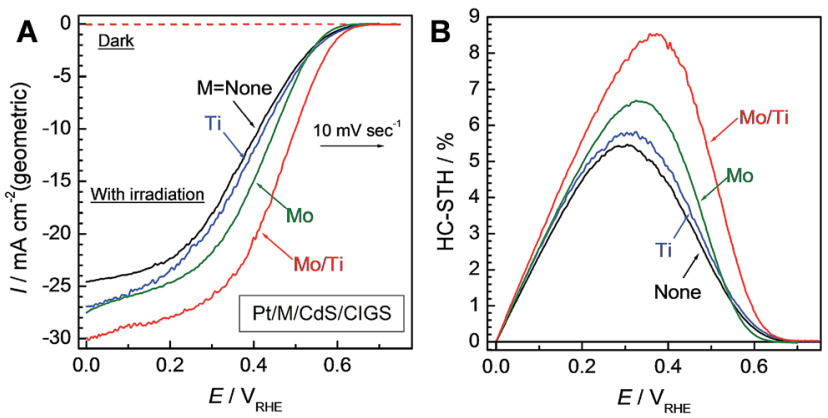

Fig. 5 (A) Current-potential curves and (B) corresponding HC-STH values of $\mathrm{Pt} / \mathrm{M} / \mathrm{CdS} / \mathrm{ClGS}$ electrodes ( $\mathrm{M}=$ none, $\mathrm{Ti}, \mathrm{Mo}$, and $\mathrm{Mo} / \mathrm{Ti}$ ) in $0.5 \mathrm{M} \mathrm{Na}_{2} \mathrm{SO}_{4}, 0.25 \mathrm{M} \mathrm{Na}_{2} \mathrm{HPO}_{4}$ and $0.25 \mathrm{M} \mathrm{NaH}_{2} \mathrm{PO}_{4}$ (aq.) (pH adjusted to 6.8 by $\mathrm{NaOH}$ addition) under AM $1.5 \mathrm{G}$ irradiation. The potential was swept toward the positive direction at $10 \mathrm{mV} \mathrm{s}^{-1}$. 
thickness on the PEC properties of the photoelectrode (Fig. S4 $\dagger$ ). In the case of the electrode modified with a thicker $\mathrm{Ti}$ layer, $6 \mathrm{~nm}$ as deposited, the photocurrent and onset potential were clearly low, which means a too thick Ti layer might prevent both charge separation and light absorption. In contrast, the electrode modified with a thicker Mo layer, $4.5 \mathrm{~nm}$ as deposited, showed a comparable onset potential to the optimal one while the photocurrent was limited. A too thick Mo layer might suppress the light absorption of CIGS.

One of the most pressing challenges associated with CIGSbased photocathodes is their lack of durability, since the cathodic photocurrent tends to decrease with use, likely due to the corrosion of CdS during the HER..$^{\mathbf{3 0 , 3 6 , 3 8}}$ To ascertain the durability of the modified CIGS photocathodes employed in the present study, variations in the photocurrent were followed over time. Fig. 6 presents current-time curves obtained from modified CIGS photocathodes, acquired with incremental steps of the applied potential between 0 and $0.5 \mathrm{~V}_{\mathrm{RHE}}$. In the case of the $\mathrm{Pt} / \mathrm{CdS} / \mathrm{CIGS}$ specimen, the photocurrent decayed rapidly for all applied potentials. In contrast, surface modification with thin single Ti or Mo layers was effective in suppressing the decrease in the cathodic photocurrent at $0 \mathrm{~V}_{\mathrm{RHE}}$, while the decrease was actually exacerbated by surface modification with single thin metal layers at $0.3 \mathrm{~V}_{\mathrm{RHE}}$. We note that the greater decrease in the photocurrent seen at this potential may have resulted from the corrosion of the Mo layer and the formation of a robust $\mathrm{TiO}_{2}$ passivation coating on the Ti layer. Interestingly, the $\mathrm{Pt} / \mathrm{Mo} / \mathrm{Ti} /$ CdS/CIGS electrode exhibited a very slow decrease in its cathodic photocurrent at all potentials.

Surface characterization of these electrodes was carried out to obtain additional insights into the nature of the conductor
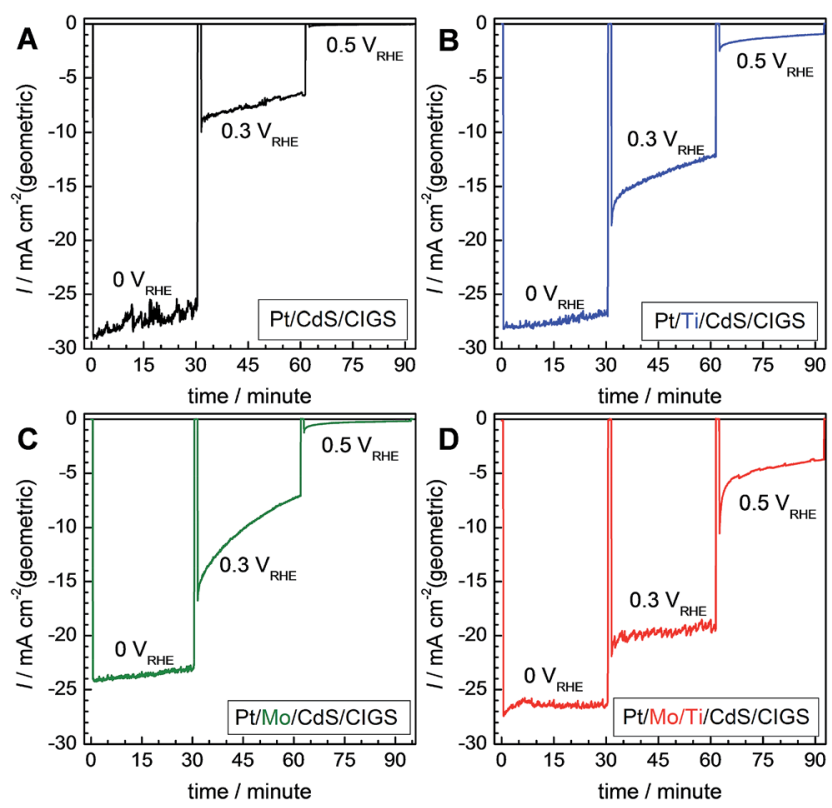

Fig. 6 Current-time plots of various modified CIGS electrodes with applied potentials of $0,0.3$ and $0.5 \mathrm{~V}_{\mathrm{RHE}}$ in $0.5 \mathrm{M} \mathrm{Na}_{2} \mathrm{SO}_{4}, 0.25 \mathrm{M}$ $\mathrm{Na}_{2} \mathrm{HPO}_{4}$ and $0.25 \mathrm{M} \mathrm{NaH}_{2} \mathrm{PO}_{4}$ (aq.) ( $\mathrm{pH}$ adjusted to 6.8 by $\mathrm{NaOH}$ addition) under $\mathrm{AM}$ 1.5G irradiation. layer of the optimal CIGS photoelectrode. An XPS analysis demonstrated that the intensities of the Mo peaks were reduced and Ti and Cd peaks appeared so that the Mo layers were partly removed following the electrodeposition of $\mathrm{Pt}$, likely due to the reduction of surface oxides during the photo-assisted electrodeposition of Pt (Fig. S5†). Comparing the escape depth of a photoelectron of Cd of approx. 10-20 angstroms to the thickness of the expected $\mathrm{Mo} / \mathrm{Ti}$ layer, which is $\sim 3 \mathrm{~nm}$ for Ti and $<3 \mathrm{~nm}$ for Mo, the resulting Mo/Ti layer partially covered the underlying CdS layer and some part of CdS might be exposed on the surface. SEM characterization showed that the $\mathrm{Pt} / \mathrm{Mo} / \mathrm{Ti}$ / CdS/CIGS electrode surface was covered with Pt particles less than $50 \mathrm{~nm}$ in size and that the portion of the Mo layer covered by Pt particles was intact (Fig. S6†). We should note that it is difficult to evaluate the exact dispersibility of loaded Pt particles due to such a small loading amount and complicated surface structure. If such relatively large Pt particles contact n-type CdS directly, the energy barrier which prevents the electron transfer can be formed simultaneously with the prevention of the CdSelectrolyte contact. The introduction of the conductor layer can be expected to avoid the formation of the undesirable energy barrier. Cross-sectional SEM observation was also carried out for each electrode of CdS/CIGS, Mo/Ti/CdS/CIGS, and Pt/Mo/Ti/ CdS/CIGS just after Pt deposition and after the PEC reaction (Fig. S7 $\dagger$ ). The CdS layer fully covered over CIGS. To confirm the transparency of the modification layer, transmittance $(T)$ and reflectance $(R)$ spectra of Mo/Ti layers on a glass plate were recorded (Fig. S8 $\dagger$ ). Using the value of $T /(1-R)(1-R)$ according to Lambert's law to evaluate the transparency without reflectance, it may be sufficient for light absorption of CIGS films. Since characterizing the surface conductivities is very helpful in studying the roles of the conductor layers, the electrical conductivities of $\mathrm{Mo} / \mathrm{Ti}$ layers on glass plates were assessed and potential contrast imaging of these samples was conducted using SEM observations. ${ }^{48}$ In this manner, the sheet resistivity of a Mo/ Ti layer was found to be approximately $200 \Omega \square^{-2}$ prior to Pt electrodeposition and approximately $2000 \Omega \square^{-2}$ afterwards. These results indicate that the conductor layers were capable of providing effective in-plane charge transfer ranging from several micrometers to ten micrometers, assuming a photocurrent of $30 \mathrm{~mA} \mathrm{~cm}^{-2}$ and an IR drop of $0.01 \mathrm{~V}$. The increased surface conductivity resulting from these layers evidently increased the ability of photo-excited electrons to reach the HER sites. Fig. 7 shows SEM images of the surfaces of CdS/CIGS and Mo/Ti/CdS/CIGS electrodes. The low-energy secondary electron images provide information concerning the surface potential contrasts while the high-energy secondary electron images primarily represent surface morphologies. When comparing these images, various unconnected dark regions representing deposited CdS particles of several tens of nanometers in size and CIGS grain boundaries are observed on the surface of the CdS/CIGS electrode, whereas the same section of the Mo/Ti/ CdS/CIGS surface is homogeneous. These images indicate that the Mo/Ti layers provided surface conductivity and that these conductor layers were able to provide an effective path for photo-excited electrons to migrate to the HER sites, i.e., the Pt particles. 


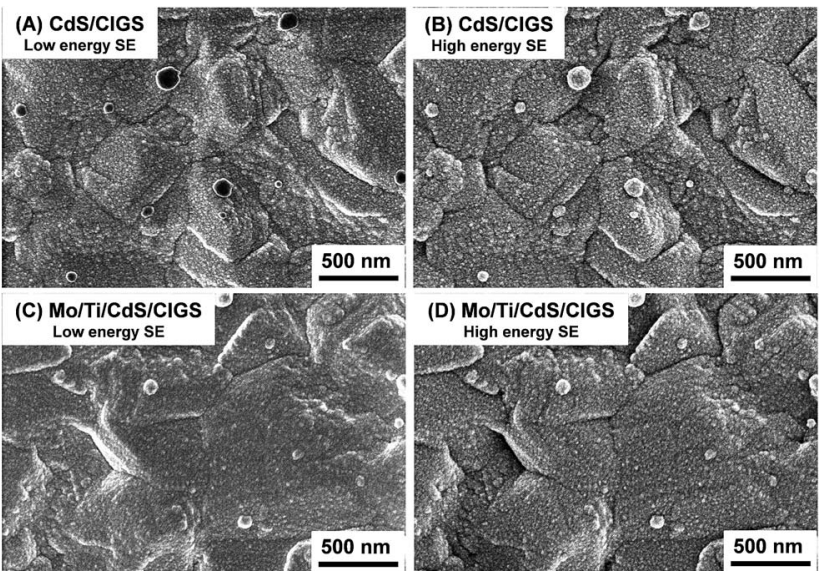

Fig. 7 SEM images of the surfaces of CdS/CIGS and Mo/Ti/CdS/CIGS electrodes: ( $A$ and $C$ ) low energy secondary electron images providing surface potential contrasts and ( $B$ and $D$ ) high energy secondary electron images representing surface morphologies.

An XPS analysis showed that the Ti layer was partially oxidized even before the PEC trials, forming oxygen-deficient $\mathrm{TiO}_{2}\left(\mathrm{TiO}_{x}\right)$, and that additional oxygen was provided during the PEC experiments, while the metallic Mo remained intact between the Pt and the $\mathrm{TiO}_{x}$ (Fig. S9†). These results demonstrate that the presence of Mo prevented the formation of a highly resistant $\mathrm{TiO}_{2}$ layer below the $\mathrm{Pt} / \mathrm{Mo}$ interface. Thus, the improved durability of this electrode resulted from the presence of both Mo and Ti layers, since these layers increased the degree of contact between the Pt particles and the Mo/Ti layer without allowing the formation of $\mathrm{TiO}_{2}$. The possible energy diagram of $\mathrm{Pt} / \mathrm{Mo} / \mathrm{Ti} / \mathrm{CdS} / \mathrm{CIGS}$ is shown in Fig. S10. $\dagger$ According to XPS results, Ti and Mo layers were described as $\mathrm{TiO}_{x}$ and $\mathrm{Mo} / \mathrm{MoO}_{2}$, respectively. The band diagram at the solid-liquid interface was calculated using the water/TiO $/$ /CdS/CIGS structure and Mo was regarded as the charge transfer layer, since Mo species can be reduced easily under hydrogen evolution conditions and remained mainly between $\mathrm{Pt}$ and $\mathrm{TiO}_{x}$, as discussed from the XPS results of Fig. S9. $\dagger$ The p-n junction formation leads to a

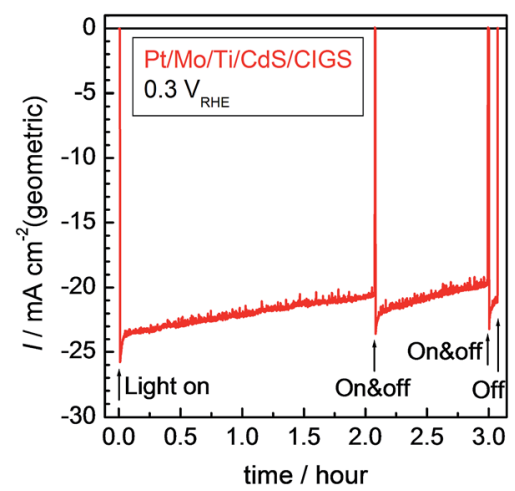

Fig. 8 Current-time plot of a Pt/Mo/Ti/CdS/CIGS electrode at an applied potential of $0.3 \mathrm{~V}_{\mathrm{RHE}}$ in $0.5 \mathrm{M} \mathrm{Na}_{2} \mathrm{SO}_{4}, 0.25 \mathrm{M} \mathrm{Na}_{2} \mathrm{HPO}_{4}$ and $0.25 \mathrm{M} \mathrm{NaH}_{2} \mathrm{PO}_{4}$ (aq.) ( $\mathrm{pH}$ adjusted to 6.8 by $\mathrm{NaOH}$ addition) under $\mathrm{AM}$ $1.5 \mathrm{G}$ irradiation.

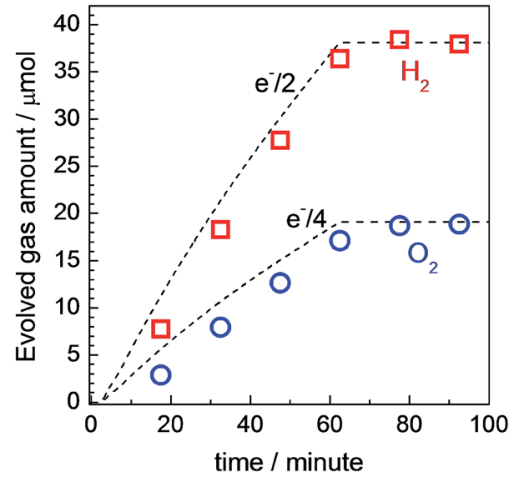

Fig. 9 Hydrogen and oxygen evolutions from a Pt/Mo/Ti/CdS/CIGS electrode (area: $0.136 \mathrm{~cm}^{2}$ ) in a three-electrode configuration with an applied potential of $0 \mathrm{~V}_{\mathrm{RHE}}$ under AM 1.5G irradiation. The theoretical evolved amounts of hydrogen and oxygen, denoted as $\mathrm{e}^{-} / 2$ and $\mathrm{e}^{-} / 4$, respectively, and calculated from the observed photocurrent are shown as dashed lines. A mixture of $0.5 \mathrm{M} \mathrm{Na}_{2} \mathrm{SO}_{4}, 0.25 \mathrm{M} \mathrm{Na}_{2} \mathrm{HPO}_{4}$ and $0.25 \mathrm{M} \mathrm{NaH}_{2} \mathrm{PO}_{4}$ (pH adjusted to 6.8 by NaOH addition) was used as the electrolyte solution.

thicker depletion layer thickness and smooth carrier transfer can be expected by the band offset of the $\mathrm{TiO}_{x} / \mathrm{CdS}$ interface. As shown in Fig. 8, the Pt/Mo/Ti/CdS/CIGS electrode generated a relatively stable photocurrent at an applied potential of 0.3 $\mathrm{V}_{\mathrm{RHE}}$. This photocurrent was readily recovered on the interruption and resumption of irradiation and almost the same photocurrent value was obtained after restarting irradiation. Long-term durability trials at a potential of $0 \mathrm{~V}_{\mathrm{RHE}}$ determined that the $\mathrm{Pt} / \mathrm{Mo} / \mathrm{Ti} / \mathrm{Cds} / \mathrm{CIGS}$ photocathode was able to continue functioning for time spans in excess of ten days, although the photocurrent decreased on a daily basis (Fig. S11†). Based on SEM observations, this decay of the photocurrent could have been due to the gradual collapse of the conductor layer structure (Fig. S12†). The limited durability of such CIGS photocathodes both over long time periods and at high potentials thus remains a challenge to be addressed.

Finally, the Faradaic efficiency of a Pt/Mo/Ti/CdS/CIGS electrode was evaluated through the analysis of evolved gases. Hydrogen and oxygen evolutions for a $\mathrm{Pt} / \mathrm{Mo} / \mathrm{Ti} / \mathrm{CdS} / \mathrm{CIGS}$ specimen and a Pt counter electrode in a three-electrode configuration with an applied potential of $0 \mathrm{~V}_{\mathrm{RHE}}$ under $\mathrm{AM}$ 1.5G irradiation are shown in Fig. 9. Comparing the hydrogen generation as determined by GC with the expected amount based on the current, the Faradaic efficiency of the Pt/Mo/Ti/ CdS/CIGS electrode was estimated to be approximately $100 \%$. Additionally, the stoichiometric evolutions of hydrogen and oxygen from water demonstrate the absence of side redox reactions other than water splitting, indicating that the $\mathrm{Pt} / \mathrm{Mo} /$ Ti/CdS/CIGS photoelectrode was able to evolve hydrogen without inducing other redox reactions which could lead to degradation of the photoelectrode.

\section{Conclusion}

Surface modified $\mathrm{Cu}(\mathrm{In}, \mathrm{Ga}) \mathrm{Se}_{2}$ polycrystalline thin film photocathodes were investigated with respect to sunlight-driven 
photoelectrochemical hydrogen production from neutral electrolyte solutions. The photocurrents of CdS and Pt-modified $\mathrm{Cu}(\mathrm{In}, \mathrm{Ga}) \mathrm{Se}_{2}$ electrodes clearly increased in phosphate buffer electrolyte solution and the associated HC-STH reached a maximum of $5.4 \%$ at $0.30 \mathrm{~V}_{\mathrm{RHE}}$ even under neutral conditions. The efficacy of the phosphate solution could be due to stabilization of the $\mathrm{pH}$ near the electrode surface and a reduced chemical bias that promotes the hydrogen evolution reaction. Additionally, surface modification with thin conductor layers composed of Mo and/or Ti was investigated to assess their effects on the charge transfer between the underlying photocathode and water through the Pt catalyst. The HC-STH of a CIGS photocathode modified with a conductive Mo/Ti layer $(\mathrm{Pt} / \mathrm{Mo} / \mathrm{Ti} / \mathrm{CdS} / \mathrm{CIGS})$ exhibited a maximum value of $8.5 \%$ at 0.38 $\mathrm{V}_{\mathrm{RHE}}$, a value that is higher than those reported for photocathodes based on polycrystalline thin films. The in-plane conductivity of modified conductor layers evidently enhanced the migration of photo-excited electrons to HER sites. It also appears that the Mo layer may come in intimate contact with the Pt particles, while the Ti layer is in contact with the underlying CdS/CIGS. The stability of the photocurrent was also improved by the presence of both a protective Ti layer and a high degree of contact between the Pt particles and the Mo/Ti layer. A Pt/Mo/Ti/ CdS/CIGS photoelectrode generated a cathodic photocurrent over a period of ten days under simulated sunlight, although exhibiting a gradual decay. These results provide valuable insights into effective means of improving the solar-tohydrogen efficiency by employing mediators to ensure smooth surface reactions and charge transfer. It can be concluded that surface modified CIGS photoelectrodes show potential for use as efficient photocathodes in solar hydrogen production via photoelectrochemical water splitting, although further development is required to allow their practical application.

\section{Acknowledgements}

This work was partly supported by the Artificial Photosynthesis Project of the Ministry of Economy, Trade and Industry (METI) of Japan, Grant-in-Aids for Specially Promoted Research (no. 23000009) and the International Exchange Program of the A3 Foresight Program of the Japan Society for the Promotion of Science (JSPS).

\section{References}

1 M. Meinshausen, N. Meinshausen, W. Hare, S. C. B. Raper, K. Frieler, R. Knutti, D. J. Frame and M. R. Allen, Nature, 2009, 458, 1158-1162.

2 H. Von Blottnitz and M. A. Curran, J. Cleaner Prod., 2007, 15, 607-619.

3 M. A. Green, K. Emery, Y. Hishikawa, W. Warta and E. D. Dunlop, Prog. Photovolt: Res. Appl., 2014, 22, 1-9.

4 Y. Tian and C. Y. Zhao, Appl. Energy, 2013, 104, 538-553.

5 J. K. Kaldellis and D. Zafirakis, Renewable Energy, 2011, 36, 1887-1901.

6 S. Chu and A. Majumdar, Nature, 2012, 488, 294-303.

7 F. E. Osterloh, Chem. Soc. Rev., 2013, 42, 2294-2320.
8 T. Hisatomi, J. Kubota and K. Domen, Chem. Soc. Rev., 2014, 43, 7520-7535.

9 A. Fujishima and K. Honda, Nature, 1972, 238, 37-38.

10 R. N. Dominey, N. S. Lewis, J. a. Bruce, D. C. Bookbinder and M. S. Wrighton, J. Am. Chem. Soc., 1982, 104, 467-482.

11 Y. Hou, B. L. Abrams, P. C. K. Vesborg, M. E. Björketun, K. Herbst, L. Bech, A. M. Setti, C. D. Damsgaard, T. Pedersen, O. Hansen, J. Rossmeisl, S. Dahl, J. K. Nørskov and I. Chorkendorff, Nat. Mater., 2011, 10, 434-438.

12 B. Seger, T. Pedersen, A. B. Laursen, P. C. K. Vesborg, O. Hansen and I. Chorkendorff, J. Am. Chem. Soc., 2013, 135, 1057-1064.

13 A. B. Laursen, T. Pedersen, P. Malacrida, B. Seger, O. Hansen, P. C. K. Vesborg and I. Chorkendorff, Phys. Chem. Chem. Phys., 2013, 15, 20000-20004.

14 B. Seger, S. D. Tilley, T. Pedersen, P. C. K. Vesborg, O. Hansen, M. Graetzel and I. Chorkendorff, RSC Adv., 2013, 3, 25902-25907.

15 E. Aharon-Shalom, J. Electrochem. Soc., 1982, 129, 2865.

16 O. Khaselev and J. A. Turner, Science, 1998, 280, 425-427.

17 M. H. Lee, K. Takei, J. Zhang, R. Kapadia, M. Zheng, Y. Z. Chen, J. Nah, T. S. Matthews, Y. L. Chueh, J. W. Ager and A. Javey, Angew. Chem., Int. Ed., 2012, 51, 10760-10764.

18 A. Heller, H. J. Leamy, B. Miller and W. D. Johnston Jr, J. Phys. Chem., 1983, 87, 3239-3244.

19 M. Katayama, D. Yokoyama, Y. Maeda, Y. Ozaki, M. Tabata, Y. Matsumoto, A. Ishikawa, J. Kubota and K. Domen, Mater. Sci. Eng., B, 2010, 173, 275-278.

20 J. Liu, T. Hisatomi, G. Ma, A. Iwanaga, T. Minegishi, Y. Moriya, M. Katayama, J. Kubota and K. Domen, Energy Environ. Sci., 2014, 7, 2239-2242.

21 S. Ida, K. Yamada, T. Matsunaga, H. Hagiwara, Y. Matsumoto and T. Ishihara, J. Am. Chem. Soc., 2010, 132, 17343-17345.

22 K. Iwashina and A. Kudo, J. Am. Chem. Soc., 2011, 133, 13272-13275.

23 C. G. Morales-Guio, S. D. Tilley, H. Vrubel, M. Grätzel and X. Hu, Nat. Commun., 2014, 5, 3059.

24 Y. Li, T. Takata, D. Cha, K. Takanabe, T. Minegishi, J. Kubota and K. Domen, Adv. Mater., 2013, 25, 125-131.

25 Y. Li, L. Zhang, A. Torres-Pardo, J. M. González-Calbet, Y. Ma, P. Oleynikov, O. Terasaki, S. Asahina, M. Shima, D. Cha, L. Zhao, K. Takanabe, J. Kubota and K. Domen, Nat. Commun., 2013, 4, 2566.

26 G. Liu, J. Shi, F. Zhang, Z. Chen, J. Han, C. Ding, S. Chen, Z. Wang, H. Han and C. Li, Angew. Chem., Int. Ed., 2014, 53, 7295-7299.

27 R. Abe, M. Higashi and K. Domen, J. Am. Chem. Soc., 2010, 11828-11829.

28 M. Higashi, K. Domen and R. Abe, J. Am. Chem. Soc., 2013, 135, 10238-10241.

29 T. Minegishi, N. Nishimura, J. Kubota and K. Domen, Chem. Sci., 2013, 4, 1120-1124.

30 D. Yokoyama, T. Minegishi, K. Maeda, M. Katayama, J. Kubota, A. Yamada, M. Konagai and K. Domen, Electrochem. Commun., 2010, 12, 851-853. 
31 M. Moriya, T. Minegishi, H. Kumagai, M. Katayama, J. Kubota and K. Domen, J. Am. Chem. Soc., 2013, 135, 3733-3735.

32 H. Kumagai, T. Minegishi, Y. Moriya, J. Kubota and K. Domen, J. Phys. Chem. C, 2014, 118, 16386-16392.

33 J. Kim, T. Minegishi, J. Kobota and K. Domen, Jpn. J. Appl. Phys., 2012, 51, 015802.

34 J. Kim, T. Minegishi, J. Kobota and K. Domen, Energy Environ. Sci., 2012, 5, 6368-6374.

35 L. Zhang, T. Minegishi, J. Kubota and K. Domen, Phys. Chem. Chem. Phys., 2014, 16, 6167-6174.

36 L. Zhang, T. Minegishi, M. Nakabayashi, Y. Suzuki, K. Seki, N. Shibata, J. Kubota and K. Domen, Chem. Sci., 2015, 6, 894-901.

37 S. Ikeda, T. Nakamura, S. M. Lee, T. Yagi, T. Harada, T. Minegishi and M. Matsumura, ChemSusChem, 2011, 4, 262-268.

38 J. Zhao, T. Minegishi, L. Zhang, M. Zhong, Gunawan, M. Nakabayashi, G. Ma, T. Hisatomi, M. Katayama, S. Ikeda, N. Shibata, T. Yamada and K. Domen, Angew. Chem., Int. Ed., 2014, 53, 11808-11812.

39 Gunawan, W. Septina, S. Ikeda, T. Harada, T. Minegishi, K. Domen and M. Matsumura, Chem. Commun., 2014, 50, 8941-8943.
40 D. Yokoyama, T. Minegishi, K. Jimbo, T. Hisatomi, G. Ma, M. Katayama, J. Kubota, H. Katagiri and K. Domen, Appl. Phys. Express, 2010, 3, 101202.

41 T. J. Jacobsson, C. Platzer-Björkman, M. Edoff and T. Edvinsson, Int. J. Hydrogen Energy, 2013, 38, 15027-15035.

42 A. M. Gabor, J. R. Tuttle, D. S. Albin, M. A. Contreras, R. Noufi and A. M. Hermann, Appl. Phys. Lett., 1994, 65, 198-200.

43 M. A. Contreras, B. Egaas, K. Ramanathan, J. Hiltner, A. Swartzlander, F. Hasoon and R. Noufi, Prog. Photovolt: Res. Appl., 1999, 7, 311-316.

44 I. Repins, M. A. Contreras, B. Egaas, C. DeHart, J. Scharf, C. L. Perkins, B. To and R. Noufi, Prog. Photovolt: Res. Appl., 2008, 16, 235-239.

45 R. Ortega-Borges, J. Electrochem. Soc., 1993, 140, 3464-3473. 46 M. Auinger, I. Katsounaros, J. C. Meier, S. O. Klemm, P. U. Biedermann, A. a. Topalov, M. Rohwerder and K. J. J. Mayrhofer, Phys. Chem. Chem. Phys., 2011, 13, 16384-16394.

47 I. Katsounaros, J. C. Meier, S. O. Klemm, A. A. Topalov, P. U. Biedermann, M. Auinger and K. J. J. Mayrhofer, Electrochem. Commun., 2011, 13, 634-637.

48 A. Miyaki, S. Takeuchi, A. Muto, Y. Dan, T. Sawahata, M. Nakagawa, T. Teranishi and Y. Majima, Microsc. Microanal., 2009, 15, 662-663. 